\title{
Prevalence and Factors Associated with Low Birth Weight and Preterm Delivery in the Ho Municipality of Ghana
}

\author{
Wisdom Kudzo Axame ${ }^{(D}$, Fred Newton Binka ${ }^{(D)}$, and Margaret Kweku \\ School of Public Health, University of Health and Allied Sciences, PMB 31, Hohoe, Volta Region, Ghana \\ Correspondence should be addressed to Wisdom Kudzo Axame; wisdomaxame@gmail.com
}

Received 10 December 2021; Revised 30 January 2022; Accepted 3 February 2022; Published 23 February 2022

Academic Editor: Daniel Diaz

Copyright () 2022 Wisdom Kudzo Axame et al. This is an open access article distributed under the Creative Commons Attribution License, which permits unrestricted use, distribution, and reproduction in any medium, provided the original work is properly cited.

\begin{abstract}
Background. Low birth weight and preterm delivery are birth outcomes that can predict newborns' survival, development, and long-term health outcomes. This study assessed the prevalence and factors associated with low birth weight and preterm delivery in the Ho Municipality of Ghana. Methods. This retrospective, cross-sectional study analysed data from 680 birth records between October and December 2018. Univariate and multivariate logistic regression models predicted low birth weight and preterm delivery factors. Results. The prevalence of low birth weight and preterm delivery was $12.9 \%$ and $14.1 \%$, respectively. Increasing maternal age (AOR: 0.52; 95\% CI: 0.28-0.98), multiparity (AOR: 0.54; 95\% CI: 0.30-0.94) and increasing doses of sulphadoxinepyrimethamine (AOR: 0.43; 95\% CI: 0.22-0.84) significantly reduced the odds of low birth weight. However, caesarean section (AOR: 1.94; 95\% CI: 0.1.16-3.27) and hypertension (AOR: 2.06; 95\% CI: 1.27-03.33) significantly increased the likelihood of low birth weight. An increasing number of antenatal care visits (AOR: 0.38; 95\% CI: $0.18-0.80$ ) and doses of sulphadoxine-pyrimethamine (AOR: 0.43; 95\% CI: 0.19-0.97) were significantly associated with decreased odds of preterm delivery, while caesarean section increased the odds of preterm delivery by two folds (AOR: 2.14; 95\% CI: 1.15-3.99). Conclusion. This study shows that maternal age, parity, number of antenatal care visits, hypertension, SP/IPTp, and caesarean section were independently associated with low birth weight and preterm delivery. Education and interventions should be prioritised as vitally important on these factors to reduce the risk and complications associated with these birth outcomes.
\end{abstract}

\section{Background}

Birth weight is an important variable that influences newborns' survival and development. It refers to the first weight taken in the first few hours of birth. Therefore, normal birth weight is crucial for neonatal survival, optimal child development, and healthier life in adulthood [1]. The World Health Organization (WHO) stipulates that the average weight that reaches full term is between 2.7 and 4.1 kilograms with an average weight of 3.5 kilograms. WHO defines low birth weight (LBW) as weight at birth of less than 2.5 kilograms/2500 grams [2]. Epidemiological data influenced this classification that newborns who weigh less than 2.5 kilograms are at increased risk of neonatal mortality compared to their heavier counterparts [3]. Preterm delivery (PTD) is described as birth of babies before 37 weeks of gestation are completed [4]. Preterm babies are at a greater risk of neonatal infections and may require more complex care, resulting in prolonged hospitalisations, increased costs, and high mortality [5].

According to WHO, the main reason for low birth weight is preterm delivery, though its aetiology remains a mystery. However, some researchers argue that morbidities and infections such as malaria, hypertension, syphilis, and HIV can cause preterm delivery $[6,7]$. Others argue that preterm delivery is caused by multiple aetiologies such as individual and environmental factors, making its prediction and prevention difficult during antenatal care $[8,9]$.

Though advances in medical research have improved birth outcomes [10], these birth outcomes remain issues of public health concern, particularly in low- and middle-income countries, as significant contributors to morbidity and mortality during neonatal, infancy, and childhood stages [11]. Different studies have reported different factors which 
influence low birth weight. For instance, a survey in China identified young maternal age, educational level a history of adverse pregnancy outcomes and maternal morbidities such as hypertensive disorders and gestational diabetes to be associated with low birth weight [12]. Several risk factors have also been reported to influence PTD. These include age, socioeconomic status, gestational diabetes, preeclampsia, and foetal distress $[13,14]$.

In sub-Saharan Africa, maternal malaria and HIV infections are significantly associated with adverse birth outcomes. In Nigeria, a study found that $14.1 \%$ of babies born to HIV-positive women had LBW compared to $1.0 \%$ in women with no HIV infection [15]. A secondary analysis of a randomised controlled trial in Malawi reported that preterm babies were born to $36.4 \%$ of women with malaria compared to $28.5 \%$ without malaria. However, the same study did not find any statistically significant difference between preterm delivery and HIV infection [6]. There are inconsistent results concerning maternal age as a factor for these birth outcomes. For instance, some studies have reported that the risk of delivering low birth weight babies among teenage mothers is higher than that of older women $[16,17]$. However, older mothers are more likely to experience these birth outcomes $[18,19]$.

In Ghana, the 2014 Ghana Demographic and Health Survey (GDHS) reported that $10 \%$ of newborns in Ghana had LBW [20]. However, the prevalence of LBW in parts of the country is higher. For instance, $26 \%$ was reported in a study in Northern Ghana in 2015 [21] and 21\% in the Ashanti region in 2013 [22]. There is no national data on the prevalence of PTD. That notwithstanding, some studies have been conducted to identify factors associated with LBW and PTD. A study in the Greater Accra region found that premature rupture of membrane and preeclampsia/eclampsia were associated with increased risk of preterm delivery while four or more antenatal care visits were protective against PTD [23]. A similar study on LBW reported anaemia, preterm delivery, education, and not taking iron supplements during pregnancy to be significantly associated with LBW [11].

The Volta Region of Ghana is reported to have aboveaverage health indicators regarding antenatal care, hospital-based deliveries, and low malnutrition indices such as underweight, wasting, and stunting. This is corroborated by findings from the 2014 GDHS that suggested the region improved health indicators compared to other regions [20]. However, the region is known to have one of the highest prevalences of teenage pregnancy, which is a known risk factor for LBW and PTD [24]. Based on the different proportions of low birth weight reported by previous research and the dearth of research on this subject matter in the region, it is vital to study the factors that influence these birth outcomes in the region.

Adequate knowledge on factors associated with these birth outcomes is crucial for identifying them and providing appropriate care and attention to at-risk pregnant women. However, little is known about factors that predispose a pregnant woman to deliver low birth weight or preterm babies in the Ho Municipality. Consequently, identifying these factors will considerably contribute to current efforts to address these issues of public health concern, which can jeopardise newborns' future. In that regard, a decline in the incidence of low birth weight and preterm babies will significantly reduce costs associated with catering for such babies, lessen the burden on the health system, and reduce the occurrence of neonatal and childhood morbidity and mortality in the region and the country as a whole. This study assessed the prevalence and factors associated with low birth weight and preterm delivery in the Ho Municipality of Ghana.

\section{Methods}

2.1. Study Site and Design. We conducted a retrospective cross-sectional study at the Ho Teaching Hospital (HTH) in the Volta Region of Ghana, which serves as the major referral hospital in the region. The hospital was established in December 2000 and was upgraded to a teaching hospital in April 2019. HTH is in the Ho Municipality, one of the 17 districts in the Volta Region. Ho Municipality has a total land area of 2,361 square kilometres. The municipality has about 49 health facilities that provide health services to its population of 177,281 . The 300 -bed capacity hospital is strategically located to render specialised health services to indigenes of the Volta Region and beyond. Clients also patronise the hospital from the Republics of Togo and Benin and the Federal Republic of Nigeria. The HTH has approximately 103,964 annual outpatients' attendance and provides about forty-one (41) essential services, including maternal and child health services. Pregnancy-related complications, anaemia, and malaria remain the top three causes of all hospital admissions [25]. Professionally trained nurses and midwives at the maternity unit of the HTH record pregnancy and birth outcome information of expectant mothers and demographic information of these mothers in delivery registers. This study examined the birth records of all mothers who delivered live babies at the HTH between October and December 2018 to identify factors associated with low birth weight and preterm delivery.

2.2. Data Extraction and Sample Size. A pretested data extraction sheet extracted maternal and newborn characteristics from paper-based delivery registers. Four trained midwives extracted the data from the registers. These midwives were oriented on the eligibility criteria for inclusion in the study and the data extraction process. Data collection was supervised daily to ensure the extracted data's consistency, completeness, and accuracy. All live births within the study period were considered for this study. However, analysis was conducted on 680 birth records after stillbirths, multiple births, babies born with congenital abnormalities (structural and functional anomalies or malformations identified at birth), and birth records with missing information were excluded. Birth records of babies born with congenital abnormalities and multiple births were excluded based on the assumption that they had different risks and aetiology for low birth weight and preterm 
delivery. Stillbirths were also excluded because they were few, and a majority had missing information on birth weight and gestational age (Figure 1). This study did not include home deliveries as health professionals did not supervise home deliveries, and as such, data on birth weight, gestation, and other maternal and child health variables used in this study were not available.

2.3. Study Variables. The outcome variables of this study were low birth weight and preterm delivery. Birth weight was dichotomised as a binary variable; 0 "normal weight" when birth weight $\geq 2.5$ kilograms and 1 "LBW" when birth weight was $<2.5$ kilograms. Similarly, gestational age was also dichotomised into 0 "carried to term" when gestational age at delivery was $\geq 37$ weeks and "PTD" when gestational age at delivery was $<37$ weeks. Gestational age was determined at birth from birth records documented by midwives. Birth records that documented ultrasound to determine gestational age were included.

Explanatory variables included maternal sociodemographic information, such as age categorised based on [20], educational level, occupation, marital status, religion, and ethnicity. Obstetric characteristics such as parity $(0=$ nulliparous, $1=$ primiparous, $2-4=$ multiparous, and $\geq 5=$ grand multiparous $)$, gravidity $(1=$ primigravida and $\geq 2$ = multigravida), type of delivery, intake of sulphadoxine pyrimethamine (SP) for intermittent preventive treatment of malaria in pregnancy (IPTp) and the number of antenatal care (ANC) visits (< four visits, four visits, and $>$ four visits) were also extracted. Additionally, maternal health conditions such as malaria, hypertension, hepatitis B and syphilis infections, and sickling status were captured. Data on maternal conditions were extracted based on routine testing of pregnant women on their first antenatal care visit. The haemoglobin level of mothers was dichotomised into normal $(\geq 11.0 \mathrm{~g} / \mathrm{dl})$ and anaemic $(<11.0 \mathrm{~g} / \mathrm{dl})$ based on WHO cutoffs [26]. These explanatory variables may influence the occurrence of LBW and PTD, as found in similar previous studies [27-29].

2.4. Data Management and Analysis. The data extraction sheets were checked for accuracy and completeness before passing on for data entry. Data entry was done using EpiData Data Entry Client (v4.4.3.1) and then exported to STATA MP/16.0 (College Station, TX, USA) for analysis. Validity and consistency checks were conducted after the data entry to ensure errors were reduced before data analysis. Descriptive statistics were used for frequencies. Percentages were reported for categorical variables.

Univariate and multivariate logistic regression analyses were performed for outcome variables. The outcomes of interest for the study variables were low birth weight and preterm delivery. Strengths of associations between outcome variables and explanatory variables were determined using crude odds ratios (Model I). Explanatory variables with $p$ values $<0.05$ in the univariate analysis (Model I) were considered for a stepwise multivariate logistic regression model (Model II). The goodness of fit of Model II was examined using the likelihood ratio test. This was done by examining the likelihood of data under the full model compared to data under an alternative model with reduced explanatory variables. The overall model recorded a $p$ value less than 0.05 , and we concluded the model was good. The variable inflation factor (VIF) was used to cater for multicollinearity. Explanatory variables with VIF values exceeding 5 were excluded from Model II as that value indicated high multicollinearity between the outcome variable and other explanatory variables. Adjusted odds ratios and confidence intervals were computed with $p$ values $<0.05$, considered statistically significant in Model II.

\section{Results}

3.1. Sociodemographic Characteristics of Women Who Delivered. Six hundred and eighty (680) women were involved in this study with a mean age of $27.5 \pm 6.18$. Women aged 20-34 years formed the majority of the participants. Few women, 96(14.1\%), had no formal education while the remaining $85.9 \%$ had varying forms of education ranging from primary school $82(12.1 \%)$ to university education 116 $(17.1 \%)$. More women, 431 (63.4\%), were employed in the private sector, and more than half 445 (65.4\%) were married. Christianity 603 (88.7\%) was the dominant religion, while Ewe was the dominant tribe (Table 1).

\subsection{Maternal Obstetric Characteristics of Women Who} Delivered. Maternal obstetric information is summarised in Table 2. The majority of the women were multiparous 238 (35.0\%) and multigravida 504 (74.1\%). A little more than a third, 238 (35.0\%), of the women had taken three doses of SP, while 218 (32.9\%) had taken more than three doses of SP. More than half, 519 (76.3\%), had more than 4 ANC visits. Based on infectious diseases, $30(4.4 \%)$ had hepatitis B infection, 6 (0.9\%) had syphilis, and 135 (19.9\%) had malaria. Less than half 102 (15\%) had hypertension, while 390 (57.4\%) had anaemia.

3.3. Prevalence of Low Birth Weight and Preterm Delivery. Out of the 680 women included in this study, the prevalence of LBW (Figure 2) was 12.9\% [95\% CI: 10.5\%-15.7\%] while that of PTD was $14.1 \%$ [95\% CI: $11.9 \%-17.3 \%$ ]. The mean birth weight was $3.03 \mathrm{~kg}( \pm 0.57)$ with a range of $0.5-4.6 \mathrm{~kg}$. Similarly, the mean gestation age was 38.7 weeks $( \pm 2.48)$ with a range of $24-44$ weeks.

\subsection{Factors Associated with Low Birth Weight.} Multivariate logistic regression was used to predict the factors associated with LBW (Table 3). In the adjusted analysis, women aged $20-34$ years had $48 \%$ lower odds of delivering LBW babies (AOR: 0.52; 95\% CI: 0.28-0.98; $p<0.05)$ than those younger than 20 years. Additionally, multiparous women had $46 \%$ lower odds of having LBW babies (AOR: 0.54; 95\% CI: 0.30-0.94; $p<0.05$ ) than their nulliparous counterparts. Women who delivered through caesarean section (CS) were $94 \%$ more likely to have LBW 


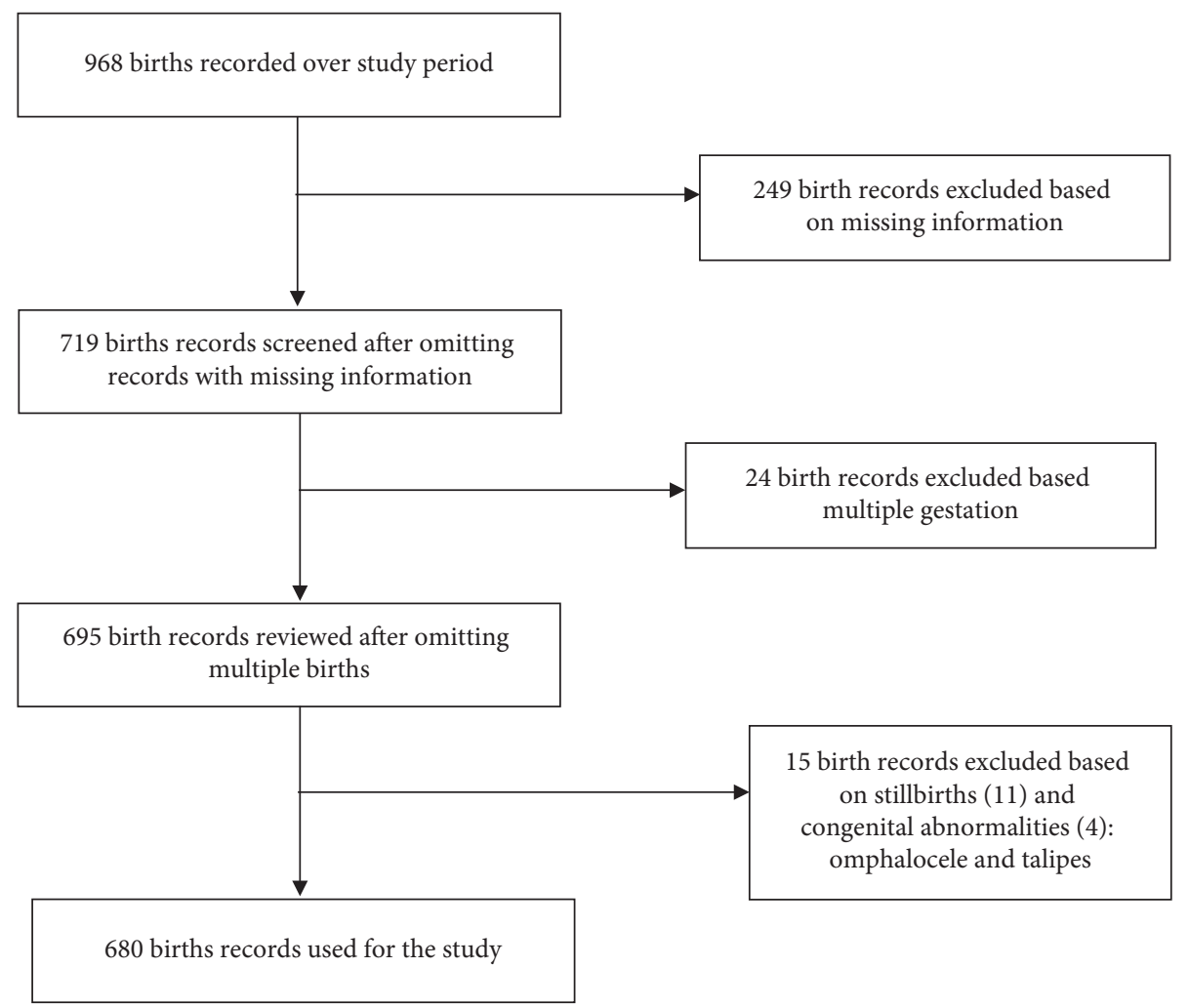

Figure 1: Flow diagram of data extraction.

babies (AOR: 1.94; 95\% CI: 0.1.16-3.27; $p<0.05$ ) compared to those who had vaginal deliveries. Furthermore, women who took more than three doses of SP for IPTp had 57\% lower odds of giving birth to LBW babies than those who took less than three doses of SP (AOR: 0.43; 95\% CI: $0.22-0.84 ; p<0.05)$. Hypertensive women were two times more likely to have low birth weight babies than normotensive women (AOR: 2.06; 95\% CI: 1.27-03.33; $p<0.05$ ).

3.5. Factors Associated with Preterm Delivery. Table 4 summarises the factors associated with preterm delivery. Women who had caesarean sections were two times more likely to have PTD than those with vaginal delivery (AOR: 2.14; 95\% CI: 1.15-3.99; $p<0.05)$. However, women with more than 4 ANC visits were $62 \%$ less likely to experience PTD (AOR: 0.38; 95\% CI: $0.18-0.80 ; p<0.05$ ) than those with less than four visits. Furthermore, women who took more than three doses of SP were also 57\% less likely to have preterm delivery than those with less than three doses (AOR: 0.43; 95\% CI: 0.19-0.97; $p<0.05$ ).

\section{Discussion}

This study sought to identify the factors associated with LBW and PTD among women in the Ho Municipality of Ghana. Overall, the study found the prevalence of LBW to be $12.9 \%$. This proportion is higher than the $10 \%$ national prevalence reported in 2014 by GDHS. The reported prevalence in this study is also higher than the $6 \%$ recorded for the Volta Region in the same 2014 by DHS [20]. The prevalence of LBW in this study is also higher than that reported in the United Arab Emirates. That study reported a prevalence of $9.4 \%$ [30]. This could be attributed to geographical differences in study sites.

Our study found that women aged 20-34 years were less likely to have LBW babies than those younger than 20 years. This is consistent with data published by Althabe and colleagues, Alemu and Umeta, and Taha and colleagues. These studies reported that teenage mothers have an increased risk of delivering LBW babies compared to older women $[16,17,30]$. However, this finding was inconsistent with $[18,19]$ who reported older women to have an increased risk of LBW compared to younger women. These results still point to the fact that inconsistent results still exist about maternal age and adverse birth outcomes, particularly LBW. Teenage mothers are most likely to be first-timers with little or no experience with the management of pregnancies. This could explain why women aged 20-34 years had fewer LBW odds than teenage mothers in this study. Additionally, teenage mothers may not be physically and emotionally mature. Thus, their bodies may be unable to deal with the stress of pregnancy [24]. Coupled with this, good maternal nutrition, socioeconomic status, and adequate ANC attendance could have made the 20-34year-old women less likely to experience LBW.

Low birth weight babies were less likely to be born to multiparous women. This is consistent with a recent study conducted in India that reported that the increased parity of a mother increased the mean birth weight of babies [31]. 
TABLE 1: Sociodemographic characteristics of women who delivered.

\begin{tabular}{lcc}
\hline Characteristics & $\begin{array}{c}\text { Frequency } \\
(N=680)\end{array}$ & $\begin{array}{c}\text { Percentage } \\
(\%)\end{array}$ \\
\hline Age (years) & & \\
$<20$ & 79 & 11.6 \\
$20-34$ & 494 & 72.7 \\
35-49 & 107 & 15.7 \\
Educational level & & \\
No formal education & 96 & 14.1 \\
Primary school & 82 & 12.0 \\
JSS/JHS/middle school & 239 & 35.2 \\
SHS/SSS/vocational & 147 & 21.6 \\
University & 116 & 17.1 \\
Occupation & & \\
Unemployed & 146 & 21.5 \\
Private sector & 431 & 63.4 \\
Public sector & 103 & 15.1 \\
Marital status & & \\
Single & 235 & 34.6 \\
Married & 445 & 65.4 \\
Religion & & \\
Christianity & 603 & 88.7 \\
Islam & 48 & 7.0 \\
African traditional & & \\
religion & 29 & 4.3 \\
Tribe & & \\
Ewe & & \\
Akan & & \\
Guan & & \\
Others & 584 & \\
\hline
\end{tabular}

Similarly, another study in Bangladesh also found that increasing parity increases birth weight leading to a reduction in the occurrence of LBW [32]. A plausible explanation for this observation might be that increased parity might lead to increased experience with pregnancy and childcare, ANC attendance, nutritional status, and health-seeking behaviour. However, this finding was incongruent with a similar study conducted in the Brong-Ahafo region of Ghana. That literature suggested that increasing parity significantly increased the odds of low birth weight [33]. Another study in Ethiopia reported similar findings to Mohammed and colleagues [34].

In this study, the odds of delivering a LBW baby were significantly higher among women who delivered their babies through CS than those with vaginal deliveries. This finding resonates with studies conducted in the United Arab Emirates [30] and China [35]. Some studies have reported an epidemic of CS, which these studies have found to increase adverse birth outcomes such as LBW and preterm delivery [36, 37]. A plausible explanation for this finding in this study could be attributed to the abuse of planned CS. A phenomenon that has been documented in an earlier study in Brazil where it was reported that CS was wrongfully associated with LBW, particularly among private hospitals [38]. In that regard, there is the need to adhere to WHO's recommendations that CS birth should not be planned before 39 completed weeks of gestation unless it is medically indicated for the benefit of either the foetus, mother or both [39]. There are inconsistent results
TABLE 2: Obstetric characteristics of women who delivered.

\begin{tabular}{|c|c|c|}
\hline Characteristics & Frequency $(N=680)$ & Percentage (\%) \\
\hline \multicolumn{3}{|l|}{ Parity } \\
\hline Nulliparous & 225 & 33.1 \\
\hline Primiparous & 191 & 28.1 \\
\hline Multiparous & 238 & 35.0 \\
\hline Grand multiparous & 26 & 3.8 \\
\hline \multicolumn{3}{|l|}{ Gravidity } \\
\hline Primigravida & 176 & 25.9 \\
\hline Multigravida & 504 & 74.1 \\
\hline \multicolumn{3}{|l|}{ Delivery type } \\
\hline Normal/vaginal & 538 & 79.1 \\
\hline Caesarean section & 140 & 20.6 \\
\hline Vacuum extraction & 2 & 0.3 \\
\hline \multicolumn{3}{|l|}{ SP/IPTp dosage } \\
\hline$<3$ & 218 & 32.1 \\
\hline 3 & 238 & 35.0 \\
\hline$>3$ & 224 & 32.9 \\
\hline \multicolumn{3}{|l|}{ ANC visits } \\
\hline$<4$ & 80 & 11.8 \\
\hline 4 & 81 & 11.9 \\
\hline$>4$ & 519 & 76.3 \\
\hline \multicolumn{3}{|l|}{ Hepatitis B infection } \\
\hline Negative & 650 & 95.6 \\
\hline Positive & 30 & 4.4 \\
\hline \multicolumn{3}{|l|}{ Syphilis infection } \\
\hline Negative & 674 & 99.1 \\
\hline Positive & 6 & 0.9 \\
\hline \multicolumn{3}{|l|}{ Hypertension status } \\
\hline Normotensive & 578 & 85.0 \\
\hline Hypertensive & 102 & 15.0 \\
\hline \multicolumn{3}{|l|}{ Anaemia status } \\
\hline Normal & 290 & 42.6 \\
\hline Anaemic & 390 & 57.4 \\
\hline \multicolumn{3}{|l|}{ Sickling status } \\
\hline Negative & 563 & 82.8 \\
\hline Positive & 117 & 17.2 \\
\hline \multicolumn{3}{|l|}{ Malaria infection } \\
\hline Negative & 545 & 80.1 \\
\hline Positive & 135 & 19.9 \\
\hline \multicolumn{3}{|l|}{ Obstetric complications } \\
\hline Absent & 657 & 96.6 \\
\hline Present & 23 & 3.4 \\
\hline
\end{tabular}

regarding the association between LBW and CS. Some studies have reported that CS is protective against low birth weight $[40,41]$, while others have shown that it increases the likelihood of LBW [42], which is similar to the current findings.

The WHO recommends pregnant women take three or more doses of sulphadoxine pyrimethamine for intermittent prevention of malaria in pregnancy (SP/IPTp) in moderate to high malaria transmission areas [43]. We found that more than three doses of SP/IPTp significantly reduced the odds of LBW. This conforms with several studies conducted in Tanzania [44, 45], Cameroon [46], Nigeria [47], and Ghana [48]. The protective nature of SP against LBW could be explained by its therapeutic effect against both malaria and nonmalaria infections. This is supported by evidence from a Zambian study that reported that SP's bacterial and parasitic effects significantly improved the birth weight of neonates born to women who took more doses of SP during 


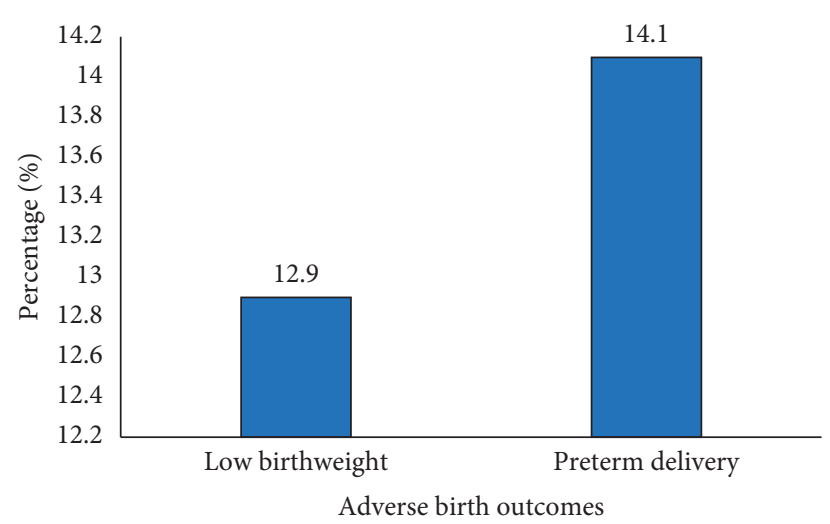

Figure 2: Prevalence of low birth weight and preterm delivery.

pregnancy. The sulphadoxine component of SP provides a broad spectrum of antiparasitic and bacterial activities [49]. Thus, constant exposure via monthly uptakes of SP could reduce microbial density and immunological reactions, leading to reduction in adverse birth outcomes, such as LBW [49-51].

Our findings further indicate that the likelihood of LBW was significantly higher among hypertensive women compared to their normotensive counterparts. This is consistent with the literature in China [52], Ethiopia [53], Brazil [54], and Haiti [55]. Some studies have linked pregnancy-induced hypertension and LBW to intrauterine growth restriction due to the placenta not receiving enough nutrients. This occurs due to poor perfusion of blood containing nutrients via the placenta. The placenta provides blood and essential nutrients for optimal growth and development from the mother to the foetus [53]. Thus, pregnancy-induced hypertension increases the risk of poor foetal nutrition hence poor foetal growth leading to LBW $[52,56]$.

The current study also identified factors associated with PTD and found that women who took more than three doses of SP had reduced odds of having a preterm birth. This resonates with data published in an earlier study in Northern Ghana, where it was reported that high uptake was significantly associated with delivery at term [57]. The uptake of more doses of SP is known to reduce the prevalence and intensity of placenta malaria and placenta parasitemia, which are significant risk factors for preterm delivery $[47,58,59]$. This finding provides valuable information on the effectiveness of SP, particularly in malaria-endemic settings. Additionally, some researchers have reported that SP may have some secondary effects on bacterial and fungal infections, promoting maternal and fetal health, thereby reducing the occurrence of preterm delivery [60-62].

The importance of antenatal care in the prevention, detection, and treatment of pregnancy-related conditions cannot be underestimated. With this, WHO recommends all pregnant women go for their first ANC visits in the first trimester of their pregnancy. This recommendation will allow for early diagnosis and management of health conditions and identify risk factors that can negatively affect the progress and outcomes of pregnancy [63]. Our study found that women with more than four ANC visits had reduced odds of delivering preterm. In Ghana, ANC services accessed by pregnant women align with WHO's recommendations, including counselling on a healthy diet and good nutrition, tobacco and substance use and physical activity, HIV and malaria prevention, tetanus vaccination, and foetal measurements and advice for dealing with physiological pregnancy symptoms such as nausea, back pain, and constipation [63]. This comprehensive ANC package could have helped identify high-risk pregnancies among the women with more ANC visits. Subsequently, measures would have been implemented to reduce these high-risk pregnancies and thus the lower risk of preterm delivery. Different studies corroborate this assertion by Cunningham and Turienzo, who emphasised how the content and type of ANC packages help reduce adverse birth outcomes $[64,65]$.

We found that babies born through caesarean section were twice as likely to be born preterm than those born through vaginal delivery. One plausible explanation could be that preterm babies were delivered through CS due to foetal compromises, such as foetal distress [66]. It could also mean that the CS was planned due to a history of previous CS or as a result of pregnancy-induced hypertension. An earlier study evaluated prolonged second-stage labour as a possible risk for subsequent preterm birth and found an association. The study reported that caesarean section done in the second stage increased the risk of preterm delivery [67].

Additionally, some studies have explained the association between second-stage CS and subsequent preterm delivery due to cervical damage. The attributed cervical damage to cervical tissue excision and uterine evacuation for abortion causes cervical trauma [68-70]. There are inconsistent results on the impact of CS on preterm delivery. Some earlier studies reported that CS improves the outcomes of preterm babies [71, 72], while others suggest vaginal birth is protective against preterm delivery [73].

4.1. Strength and Limitation. This is the first study to investigate the factors associated with low birth weight and preterm delivery in the Ho Municipality of Ghana. However, it is not without limitations. First, data used for analysis in this study was collected for routine healthcare services and 
TABle 3: Association between sociodemographic, obstetric characteristics, maternal health conditions, and the odds of low birth weight.

\begin{tabular}{|c|c|c|c|}
\hline Characteristic & Low birth weight $(N=88), n(\%)$ & COR $(95 \% \mathrm{CI}), p$ value model I & AOR $(95 \% \mathrm{CI}), p$ value model II \\
\hline \multicolumn{4}{|l|}{ Age (years) } \\
\hline$<20$ & $17(19.3)$ & Ref. & Ref. \\
\hline $20-34$ & $56(63.6)$ & $0.47(0.25,0.85), 0.013$ & $0.52(0.28,0.98), 0.043$ \\
\hline $35-49$ & $15(17.1)$ & $0.59(0.27,1.28), 0.183$ & $0.65(0.29,1.43), 0.286$ \\
\hline \multicolumn{4}{|l|}{ Educational level } \\
\hline No formal education & $12(13.6)$ & Ref. & \\
\hline Primary school & $14(15.9)$ & $1.44(0.63,3.32), 0.391$ & \\
\hline JSS/JHS/middle school & $31(35.2)$ & $1.04(0.51,2.13), 0.907$ & \\
\hline SHS/SSS/vocational & $21(23.9)$ & $1.17(0.54,2.50), 0.691$ & \\
\hline University & $10(11.4)$ & $0.66(0.27,1.60), 0.359$ & \\
\hline \multicolumn{4}{|l|}{ Occupation } \\
\hline Unemployed & $21(23.9)$ & Ref. & \\
\hline Private sector & $58(65.9)$ & $0.92(0.54,1.59), 0.778$ & \\
\hline Public sector & $9(10.2)$ & $0.57(0.24,1.30), 0.182$ & \\
\hline \multicolumn{4}{|l|}{ Marital status } \\
\hline Single & $41(46.6)$ & Ref. & \\
\hline Married & $47(53.4)$ & $0.56(0.36,8.88), 0.012$ & \\
\hline \multicolumn{4}{|l|}{ Parity } \\
\hline Nulliparous & $38(43.2)$ & Ref. & Ref. \\
\hline Primiparous & $24(27.3)$ & $0.71(0.41,1.23), 0.219$ & $0.74(0.42,1.29), 0.291$ \\
\hline Multiparous & $22(25.0)$ & $0.50(0.29,0.88), 0.016$ & $0.54(0.30,0.94), 0.031$ \\
\hline Grand multiparous & $4(5.5)$ & $0.89(0.29,2.74), 0.846$ & $0.84(0.23,2.55), 0.757$ \\
\hline \multicolumn{4}{|l|}{ Gravidity } \\
\hline Primigravida & $28(31.8)$ & Ref. & \\
\hline Multigravida & $60(68.2)$ & $0.71(0.43,1.16), 0.174$ & \\
\hline \multicolumn{4}{|l|}{ Delivery type } \\
\hline Normal/vaginal & $62(70.4)$ & Ref. & Ref. \\
\hline Caesarean section & $26(29.6)$ & $1.76(1.07,2.90), 0.025$ & $1.94(1.16,3.27), 0.012$ \\
\hline Vacuum extraction & $0(0.0)$ & $1.52(0.07,3.21), 0.786$ & $1.96(0.09,4.20), 0.666$ \\
\hline \multicolumn{4}{|l|}{ SP/IPTp dosage } \\
\hline$<3$ & $40(45.4)$ & Ref. & Ref. \\
\hline 3 & $32(36.4)$ & $0.69(0.42,1.15), 0.153$ & $0.91(0.52,1.60), 0.739$ \\
\hline$>3$ & $16(18.2)$ & $0.34(0.18,0.63), 0.001$ & $0.43(0.22,0.84), 0.013$ \\
\hline \multicolumn{4}{|l|}{ ANC visits } \\
\hline$<4$ visits & $12(13.6)$ & Ref. & \\
\hline 4 visits & $16(18.2)$ & $1.39(0.61,3.17) 0.428$ & \\
\hline$>4$ visits & $60(68.2)$ & $0.74(0.38,1.45) 0.380$ & \\
\hline \multicolumn{4}{|l|}{ Hepatitis B infection } \\
\hline Negative & $81(92.1)$ & Ref. & \\
\hline Positive & $7(7.9)$ & $2.13(0.89,5.14) 0.090$ & \\
\hline \multicolumn{4}{|l|}{ Syphilis infection } \\
\hline Negative & $85(96.6)$ & Ref. & \\
\hline Positive & $3(3.4)$ & $6.93(1.38,34.89) 0.019$ & \\
\hline \multicolumn{4}{|l|}{ Hypertension status } \\
\hline Normotensive & $53(60.2)$ & Ref. & Ref. \\
\hline Hypertensive & $35(39.8)$ & $1.98(1.24,3.16) 0.004$ & $2.06(1.27,3.33), 0.003$ \\
\hline \multicolumn{4}{|l|}{ Anaemia status } \\
\hline Normal & $35(39.8)$ & Ref. & \\
\hline Anaemic & $53(60.2)$ & $1.28(0.81,2.03) 0.278$ & \\
\hline \multicolumn{4}{|l|}{ Sickling status } \\
\hline Negative & $70(79.5)$ & Ref. & \\
\hline Positive & $18(20.5)$ & $1.28(0.73,2.24) 0.388$ & \\
\hline \multicolumn{4}{|l|}{ Malaria infection } \\
\hline Negative & $60(68.2)$ & Ref. & Ref. \\
\hline Positive & $28(31.8)$ & $2.11(1.28,3.47) 0.003$ & $1.50(0.86,2.64), 0.156$ \\
\hline
\end{tabular}

not primarily for research. There is a possibility of measurement errors regarding readings and recordings of critical variables such as birth weight and other explanatory variables occurring during documentation. However, the effects of these errors were random and unlikely to interfere with the results of this study. The study included hospitalbased deliveries excluding home deliveries; as such, findings should be interpreted with caution. That notwithstanding, 
TABLE 4: Association between sociodemographic, obstetric characteristics, maternal health conditions, and the odds of preterm delivery.

\begin{tabular}{|c|c|c|c|}
\hline Characteristic & Preterm delivery $[N=96] n(\%)$ & COR $(95 \%$ CI $) p$ value model I & AOR $(95 \%$ CI $) p$ value model II \\
\hline \multicolumn{4}{|l|}{ Age (years) } \\
\hline$<20$ & $21(21.9)$ & Ref. & Ref. \\
\hline $20-34$ & $60(62.5)$ & $0.38(0.22,0.67), 0.001$ & $0.63(0.30,1.33), 0.231$ \\
\hline $35-49$ & $15(15.6)$ & $0.45(0.21,0.94), 0.034$ & $0.88(0.35,2.21), 0.791$ \\
\hline \multicolumn{4}{|l|}{ Educational level } \\
\hline No formal education & $21(21.9)$ & Ref. & \\
\hline Primary school & $11(11.5)$ & $0.55(0.25,1.23), 0.146$ & \\
\hline JSS/JHS/middle school & $34(35.4)$ & $0.59(0.32,1.08), 0.090$ & \\
\hline SHS/SSS/vocational & $18(18.8)$ & $0.50(0.25,0.99), 0.048$ & \\
\hline University & $12(12.5)$ & $0.41(0.19,0.89), 0.024$ & \\
\hline \multicolumn{4}{|l|}{ Occupation } \\
\hline Unemployed & $25(26.0)$ & Ref. & \\
\hline Private sector & $60(62.5)$ & $0.78(0.47,1.30), 0.346$ & \\
\hline Public sector & $11(11.5)$ & $0.58(0.27,1.24), 0.158$ & \\
\hline \multicolumn{4}{|l|}{ Marital status } \\
\hline Single & $46(47.9)$ & Ref. & \\
\hline Married & $50(52.1)$ & $0.52(0.34,0.80), 0.003$ & \\
\hline \multicolumn{4}{|l|}{ Parity } \\
\hline Primiparous & $38(39.6)$ & Ref. & \\
\hline Multiparous & $58(60.4)$ & $0.72(0.46,1.12), 0.146$ & \\
\hline \multicolumn{4}{|l|}{ Gravidity } \\
\hline Nulliparous & $38(39.6)$ & Ref. & \\
\hline Primiparous & $22(22.9)$ & $0.64(0.36,1.13), 0.122$ & \\
\hline Multiparous & $29(30.2)$ & $0.68(0.40,1.15), 0.152$ & \\
\hline Grand multiparous & $7(7.3)$ & $1.81(0.71,4.61), 0.212$ & \\
\hline \multicolumn{4}{|l|}{ Delivery type } \\
\hline Normal/vaginal & $69(71.9)$ & Ref. & Ref. \\
\hline Caesarean section & $27(28.1)$ & $1.63(1.01,2.66), 0.047$ & $2.14(1.15,3.99), 0.016$ \\
\hline Vacuum extraction & $0(0.0)$ & $1.35(0.06,2.84), 0.847$ & $2.40(0.11,5.24), 0.578$ \\
\hline \multicolumn{4}{|l|}{ SP/IPTp dosage } \\
\hline$<3$ doses & $52(54.2)$ & Ref. & Ref. \\
\hline 3 doses & $30(31.2)$ & $0.46(0.28,0.75), 0.002$ & $0.77(0.41,1.45), 0.422$ \\
\hline$>3$ doses & $14(14.6)$ & $0.21(0.11,0.40),<0.001$ & $0.43(0.19,0.97), 0.041$ \\
\hline \multicolumn{4}{|l|}{ ANC visits } \\
\hline$<4$ & $23(24.0)$ & Ref. & Ref. \\
\hline 4 & $22(22.9)$ & $0.92(0.46,1.84), 0.822$ & $0.87(0.38,2.01), 0.750$ \\
\hline$>4$ & $51(53.1)$ & $0.27,(0.15,0.47),<0.001$ & $0.38(0.18,0.80), 0.010$ \\
\hline \multicolumn{4}{|l|}{ Hepatitis B infection } \\
\hline Negative & $92(95.8)$ & Ref. & \\
\hline Positive & $4(4.2)$ & $0.93(0.31,2.74), 0.900$ & \\
\hline \multicolumn{4}{|l|}{ Syphilis infection } \\
\hline Negative & $94(97.9)$ & Ref. & \\
\hline Positive & $2(2.1)$ & $3.08(0.56,17.08), 0.197$ & \\
\hline \multicolumn{4}{|l|}{ Hypertension status } \\
\hline Normotensive & $83(86.5)$ & Ref. & \\
\hline Hypertensive & $13(13.5)$ & $0.94(0.58,1.55), 0.836$ & \\
\hline \multicolumn{4}{|l|}{ Anaemia status } \\
\hline Normal & $37(38.5)$ & Ref. & Ref. \\
\hline Anaemic & $59(61.5)$ & $2.27(1.27,4.03), 0.005$ & $1.69(0.92,3.10), 0.092$ \\
\hline \multicolumn{4}{|l|}{ Sickling status } \\
\hline Negative & $77(80.2)$ & Ref. & \\
\hline Positive & $19(19.8)$ & $1.22(0.71,2.11), 0.469$ & \\
\hline \multicolumn{4}{|l|}{ Malaria infection } \\
\hline Negative & $61(63.5)$ & Ref. & \\
\hline Positive & $35(36.5)$ & $2.78(1.73,4.43),<0.001$ & \\
\hline
\end{tabular}


routine healthcare services data can be used to plan, monitor, and evaluate public health interventions.

\section{Conclusion}

Evidence from this study indicates that maternal age, parity, number of ANC visits, hypertension, SP/IPTp, and caesarean section were independent factors associated with LBW and PTD. These findings add to the literature on the factors associated with these adverse birth outcomes, particularly in resource-limited environments. Furthermore, this study could serve as a foundation for further research in the study area and develop public health interventions to reduce the risk and complications of these birth outcomes.

\section{Data Availability}

All data and materials are available upon reasonable request from the corresponding author.

\section{Ethical Approval}

This study received ethical approval from the Research Ethics Committee of the University of Health and Allied Sciences (UHAS-REC A. [6] 18-19).

\section{Disclosure}

A preprint of this manuscript has previously been published [74].

\section{Conflicts of Interest}

The authors declare that there are no conflicts of interest regarding the publication of this paper.

\section{Authors' Contributions}

WKA, FNB, and MK conceived the study and were responsible for the initial draft of the manuscript. WKA did the data analysis and wrote the methods section. All authors reviewed and approved the final version of the manuscript.

\section{Acknowledgments}

The authors are grateful to Dr. John Tampuri and the management and staff of Ho Teaching Hospital for allowing them to conduct this study in their facility. They are grateful to the records staff of Ho Teaching Hospital for their support and assistance. They are also grateful to the research assistants who helped extract the data. Many thanks are also due to Mr. Martin Adjuik for guidance during data analysis.

\section{References}

[1] I. A. Awintuen, E. W. Kanmiki, A. Nonterah et al., "Sociodemographic determinants of low birth weight: evidence from the kassena-nankana districts of the upper east region of Ghana," PLoS One, vol. 13, no. 11, pp. 1-10, Article ID $0206207,2018$.
[2] World Health Organization, "Resolution WHA65.6. Comprehensive implementation plan on maternal, infant and young child nutrition," in Proceedings of the Sixty-fifth World Health Assembly Geneva, 21-26 May 2012, Geneva, Switzerland, May 2012.

[3] United Nations Children's Fund, World Health Organization, Filcher of Good Names: An Enquiry into Anthropology and GossipWHO Publications, Geneva, Switzerland, 2004.

[4] World Health Organization, WHO Factsheets on Preterm Delivery, WHO, Geneva, Switzerland, 2018.

[5] World Health Organization, Preterm Babies: Fact Sheet 363WHO Publications, Geneva, Switzerland, 2016.

[6] N. R. van der Broek, R. Jean-Baptiste, and J. P. Neilson, "Factors associated with preterm, early preterm and late preterm birth in Malawi," PLoS One, vol. 9, no. 3, Article ID e90128, 2014.

[7] M. Gebremedhin, F. Ambaw, E. Admassu, and H. Berhane, "Maternal associated factors of low birth weight: a hospital based cross-sectional mixed study in Tigray, Northern Ethiopia," BMC Pregnancy and Childbirth, vol. 15, no. 1, p. 222, 2015.

[8] Z. A. Oskovi Kaplan and A. S. Ozgu-Erdinc, "Prediction of preterm birth: maternal characteristics, ultrasound markers, and biomarkers: an updated overview," J Pregnancy, vol. 2018, Article ID 8367571, 2018.

[9] H. Torchin and P.-Y. Ancel, "Épidémiologie et facteurs de risque de la prématurité," Journal de Gynécologie Obstétrique et Biologie de la Reproduction, vol. 45, no. 10, pp. 1213-1230, 2016.

[10] R. A. Abdo, T. B. Endalemaw, and F. Y. Tesso, "Prevalence and associated factors of adverse birth outcomes among women attended maternity ward at negest elene mohammed memorial journal of women's health care," Journal of Women's Health Care, vol. 5, no. 4, pp. 3-7, 2016.

[11] Z. Adam, D. K. Ameme, P. Nortey, E. A. Afari, and E. Kenu, "Determinants of low birth weight in neonates born in three hospitals in Brong Ahafo Region, Ghana, 2016- an unmatched case-control study," BMC Pregnancy and Childbirth, vol. 19, no. 1, pp. 174-179, 2019.

[12] Y. Chen, G. Li, Y. Ruan, L. Zou, X. Wang, and W. Zhang, "An epidemiological survey on low birth weight infants in China and analysis of outcomes of full-term low birth weight infants," BMC Pregnancy and Childbirth, vol. 13, no. 242, p. 242, 2013.

[13] S. Weinmann, A. Naleway, G. Swamy et al., "Pregnancy outcomes after treatment for cervical cancer precursor lesions: an observational study," PLoS One, vol. 12, no. 1, Article ID e0165276, 2017.

[14] P. Wagura, A. Wasunna, A. Laving, D. Wamalwa, and P. Ng'ang'a, "Prevalence and factors associated with preterm birth at Kenyatta national hospital," BMC Pregnancy and Childbirth, vol. 18, no. 1, p. 107, 2018.

[15] C. O. Agboghoroma and Z. Iliyasu, "Hiv prevalence and trends among pregnant women in abuja, Nigeria: a 5-year analysis," Tropical Journal of Obstetrics and Gynaecology, vol. 32, 2015.

[16] F. Althabe, J. L. Moore, L. Gibbons, M. Berrueta, S. S. Goudar, and E. Chomba, "Adverse maternal and perinatal outcomes in adolescent pregnancies: the Global Network's maternal newborn health registry study," Reproductive Health, vol. 12, no. 2, p. S8, 2015.

[17] T. Alemu and M. Umeta, "Prevalence and determinants of small size babies in Ethiopia: results from in-depth analyses of the Ethiopian Demographic and Health Survey-2011," Family Medicine and Medical Science Research, vol. 4, no. 171, 2015. 
[18] L. Tshotetsi, L. Dzikiti, P. Hajison, and S. Feresu, "Maternal factors contributing to low birth weight deliveries in Tshwane District, South Africa," PLoS One, vol. 14, no. 3, Article ID e0213058, 2019.

[19] A. Talie, M. Taddele, and M. Alemayehu, "Magnitude of low birth weight and associated factors among newborns delivered in dangla primary hospital, amhara regional state, northwest Ethiopia, 2017," J Pregnancy, vol. 2019, Article ID 3587239, 2019.

[20] Ghana Statistical Service, Ghana Health Service, ICF International, and ICF Macro, Ghana Demographic and Health Survey, 2014, ICF Macro, Rockville, Maryland, USA, 2014.

[21] A. Abukari, G. Kynast-Wolf, and A. Jahn, "Maternal determinants of birth weight in northern Ghana," PLoS One, vol. 10, Article ID e0135641, 2015.

[22] O. F. Michael, I. Abdul-Rahman, and R. Yekeen, "Maternal risk factors for low birth weight in a District Hospital in Ashanti Region of Ghana," Res Obstet Gynaecol, vol. 2, pp. 48-54, 2013.

[23] E. K. Aseidu, D. A. Bandoh, D. K. Ameme et al., "Obstetric determinants of preterm delivery in a regional hospital, Accra, Ghana 2016," BMC Pregnancy and Childbirth, vol. 19, no. 1, pp. 248-8, 2019.

[24] F. Agbozo, A. Abubakari, J. Der, A. Jahn, M. P. Lecturer, and A. Jahn, "Prevalence of low birth weight, macrosomia and stillbirth and their relationship to associated maternal risk factors in Hohoe Municipality, Ghana," Midwifery, vol. 40, pp. 200-6, 2016.

[25] Volta Regional Health Directorate, Annual Report, 2018, Volta Regional Health Directorate, Ho, Ghana, 2018.

[26] World Health Organization, Vitamin and Mineral Nutrition Information System, World Health Organization, Geneva, Switzerland, Haemoglobin Concentrations for the Diagnosis of Anaemia and Assessment of Severity, 2011.

[27] A. Abubakari, G. Kynast-Wolf, and A. Jahn, "Prevalence of abnormal birth weight and related factors in northern region, Ghana," BMC Pregnancy and Childbirth, vol. 15, no. 335, pp. 335-338, 2015.

[28] C. Yilgwan, H. Hyacinth, and T. Utoo, "Maternal characteristics influencing birth weight and infant weight gain in the first 6 weeks post-partum: a cross-sectional study of a postnatal clinic population," Nigerian Medical Journal, vol. 53, no. 4, pp. 200-205, 2012.

[29] G. Bugussa, B. Dimtsu, and M. Alemayehu, "Socio demographic and maternal determinants of low birth weight at Mekelle hospital , northern Ethiopia: a cross sectional study," American Journal of Advanced Drug Delivery, vol. 2, no. 5, pp. 609-618, 2014.

[30] Z. Taha, A. Ali Hassan, L. Wikkeling-scott, and D. Papandreou, "Factors associated with preterm birth and low birth weight in abu dhabi, the United Arab Emirates," International Journal of Environmental Research and Public Health, vol. 17, no. 1382, pp. 1-10, 2020.

[31] R. G. Narwade and U. B. More, "The effects of maternal age and parity on birth weight in a tribal community of Kinwat, Nanded, Maharashtra, India," International Journal of Reproduction, Contraception, Obstetrics and Gynecology, vol. 7, no. 11, pp. 4451-4453, 2018.

[32] M. K. Ali, M. S. A. Quarashi, S. Sultana, and M. Z. Rahman, "Observation of birth weight of babies in relation on maternal age, parity and gestational age in tertiary level hospital," Bangladesh Journal of Medical Science, vol. 19, no. 2, pp. 291-295, 2020.
[33] S. Mohammed, I. Bonsing, I. Yakubu, and W. P. Wondong, "Maternal obstetric and socio-demographic determinants of low birth weight: a retrospective cross-sectional study in Ghana," Reproductive Health, vol. 16, no. 70, pp. 70-78, 2019.

[34] A. Bekele, G. Seyoum, K. Tesfaye, and Y. Fantahun, "The effects of maternal age and parity on the birth weight of newborns among mothers with singleton pregnancies and at term deliveries," The Ethiopian Journal of Health Development, vol. 33, no. 3, pp. 1-6, 2019.

[35] Y. Chen, L. Wu, W. Zhang, L. Zou, G. Li, and L. Fan, "Delivery modes and pregnancy outcomes of low birth weight infants in China," Journal of Perinatology, vol. 36, no. 1, pp. 41-46, 2016.

[36] F. C. Barros, D. d. L. Rabello Neto, J. Villar et al., "Caesarean sections and the prevalence of preterm and early-term births in Brazil: secondary analyses of national birth registration," BMJ Open, vol. 8, no. 8, Article ID e021538, 2018.

[37] M. L. Ada, M. R. Hacker, T. H. Golen, M. J. Haviland, S. A. Shainker, and H. H. Burris, "Trends in provider-initiated versus spontaneous preterm deliveries, 2004-2013," Journal of Perinatology, vol. 37, no. 11, pp. 1187-1191, 2017.

[38] E. F. C. Murta, G. C. Freire, D. C. Fabri, and R. H. Fabri, "Could elective cesarean sections influence the birth weight of full-term infants?” Sao Paulo Medical Journal, vol. 124, no. 6, pp. 313-315, 2006.

[39] World Health Organization, WHO Recommendations on Interventions to Improve Preterm Birth Outcomes, World Health Organization, Geneva, Switzerland, 2015.

[40] R. H. Al. Rifai, "Trend of caesarean deliveries in Egypt and its associated factors: evidence from national surveys, 2005-2014," BMC Pregnancy and Childbirth, vol. 17, no. 417, pp. 1-14, 2017.

[41] L. D. Hailu and D. L. Kebede, "Determinants of low birth weight among deliveries at a referral hospital in northern Ethiopia," BioMed Research International, vol. 2018, Article ID 8169615, 2018.

[42] M. Momeni, M. Danaei, A. J. Kermani et al., "Prevalence and risk factors of low birth weight in the southeast of Iran," International Journal of Preventive Medicine, vol. 8, no. 12, p. 12, 2017.

[43] WHO, Intermittent Preventive Treatment in Pregnancy (IPTP) WHO World Health Organization, Geneva, Switzerland, 2018.

[44] E. M. Mlugu, O. Minzi, M. Asghar, A. Färnert, A. A. R. Kamuhabwa, and E. Aklillu, "Pathogens E ff ectiveness of sulfadoxine - pyrimethamine for intermittent preventive treatment of malaria and adverse birth outcomes in pregnant women," Pathogens, vol. 9, no. 207, pp. 1-19, 2020.

[45] W. P. Mikomangwa, O. M. S. Minzi, E. Aklillu, and A. A. R. Kamuhabwa, "Adverse birth outcomes among mothers who received intermittent preventive treatment with Sulphadoxine- Pyrimethamine in the low malaria transmission region," BMC Pregnancy and Childbirth, vol. 1, no. 236, pp. 1-11, 2019.

[46] J. K. A. Anchang-Kimbi, L. N. Kalaji, H. F. Mbacham et al., "Coverage and effectiveness of intermittent preventive treatment in pregnancy with sulfadoxine-pyrimethamine (IPTp-SP) on adverse pregnancy outcomes in the Mount," Malaria Journal, vol. 19, no. 100, pp. 1-12, 2020.

[47] D. A. Isah, A. Y. Isah, Y. Thairu, and E. T. Agida, "Effectiveness of 3 doses of intermittent preventive therapy with sulphadoxine-pyrimethamine in pregnancy," Annals of Medical and Health Sciences Research, vol. 7, pp. 52-57, 2017.

[48] I. Quakyi, B. Tornyigah, P. Houze et al., "High uptake of Intermittent Preventive Treatment of malaria in pregnancy is 
associated with improved birth weight among pregnant women in Ghana," Scientific Reports, vol. 9, pp. 19034-19112, 2019.

[49] M. C. D. Stoner, B. Vwalika, M. Smid et al., "Dosage of sulfadoxine-pyrimethamine and risk of low birth weight in a cohort of Zambian pregnant women in a low malaria prevalence region," The American Journal of Tropical Medicine and Hygiene, vol. 96, no. 1, pp. 170-177, 2017.

[50] M. Capan, G. Mombo-Ngoma, A. Makristathis, and M. Ramharter, "Anti-bacterial activity of intermittent preventive treatment of malaria in pregnancy: comparative in vitro study of sulphadoxine-pyrimethamine, mefloquine, and azithromycin," Malaria Journal, vol. 9, no. 303, p. 303, 2010.

[51] R. M. Chico and W. J. Moss, "Prevention of malaria in pregnancy: a fork in the road?” The Lancet, vol. 386, no. 10012, pp. 2454-2456, 2015.

[52] F. Lei, D. Liu, Y. Shen et al., "Study on the influence of pregnancy-induced hypertension on neonatal birth weight," Journal of Investigative Medicine, vol. 66, pp. 1-7, 2018.

[53] E. A. Lake and R. O. Fite, "Low birth weight and its associated factors among newborns delivered at wolaita sodo university teaching and referral hospital , southern Ethiopia, 2018," Int $J$ Paediatr, vol. 20196 pages, 2019.

[54] S. S. da Cruz, I. S. Gomes-filho, J. D. S. Passos-soares et al., "Maternal hypertension as a risk factor Associated with low birth weight," Brazilian J Med Hum Heal, vol. 4, no. 2, pp. 49-56, 2016.

[55] M. Bridwell, E. Handzel, M. Hynes et al., "Hypertensive disorders in pregnancy and maternal and neonatal outcomes in Haiti: the importance of surveillance and data collection," BMC Pregnancy and Childbirth, vol. 19, no. 208, pp. 208-211, 2019.

[56] J. C. H. Tsang, J. S. L. Vong, L. Ji et al., "Integrative single-cell and cell-free plasma RNA transcriptomics elucidates placental cellular dynamics," Proceedings of the National Academy of Sciences, vol. 114, no. 37, pp. E7786-E7795, 2017.

[57] F. Anto, I. H. Agongo, V. Asoala, E. Awini, and A. R. Oduro, "Intermittent preventive treatment of malaria in pregnancy: assessment of the sulfadoxine-pyrimethamine three-dose policy on birth outcomes in rural northern Ghana," Journal of Tropical Medicine, vol. 2019, Article ID 6712685, 10 pages, 2019.

[58] WHO, Malaria in Pregnant WomenWHO, Geneva, Switzerland, 2017.

[59] R. M. Chico, E. B. Chaponda, C. Ariti, and D. Chandramohan, "Sulfadoxine-pyrimethamine exhibits dose-response protection against adverse birth outcomes related to malaria and sexually transmitted and reproductive tract infection," Clinical Infectious Diseases, vol. 64, no. 8, pp. 1043-1051, 2017.

[60] H. W. Unger, A. P. Hansa, C. Buffet et al., "Sulphadoxine-pyrimethamine plus azithromycin may improve birth outcomes through impacts on inflammation and placental angiogenesis independent of malarial infection," Scientific Reports, vol. 9, no. 2260 , pp. 2260-2312, 2019.

[61] S. C. Azizi, "Uptake of intermittent preventive treatment for malaria during pregnancy with Sulphadoxine-Pyrimethamine in Malawi after adoption of updated World Health Organization policy: an analysis of demographic and health survey 2015 - 2016," BMC Public Health, vol. 20, no. 335, pp. 1-12, 2020.

[62] V. N. Orish, O. S. Onyeabor, J. N. Boampong et al., "Prevalence of intermittent preventive treatment with sulphadoxine-pyrimethamine (IPTp-SP) use during pregnancy and other associated factors in Sekondi-Takoradi, Ghana," African Health Sciences, vol. 15, no. 4, pp. 1087-1096, 2015.
[63] WHO, Sexual and Reproductive Health New Guidelines on Antenatal Care for a Positive Pregnancy ExperienceWHO, Geneva, Switzerland, 2016.

[64] S. D. Cunningham, J. B. Lewis, F. M. Shebl et al., "Group prenatal care reduces risk of preterm birth and low birth weight," Journal of Women's Health, vol. 00, no. 00, pp. 1-6, 2018.

[65] C. F. Turienzo, J. Sandall, and J. L. Peacock, "Models of antenatal care to reduce and prevent preterm birth: a systematic review and meta-analysis," BMJ Open, vol. 6, no. e009044, pp. 1-13, 2016.

[66] B. Y. L. Thanh, P. Lumbiganon, P. Pattanittum et al., "Mode of delivery and pregnancy outcomes in preterm birth: a secondary analysis of the WHO Global and Multi-country Surveys," Scientific Reports, vol. 9, no. 15556, pp. 15556-15558, 2019.

[67] N. A. Vyas, J. S. Vink, A. Ghidini et al., "Risk factors for cervical insufficiency after term delivery," American Journal of Obstetrics and Gynecology, vol. 195, no. 3, pp. 787-791, 2006.

[68] L. D. Levine and S. K. Srinivas, "Length of second stage of labor and preterm birth in a subsequent pregnancy," American Journal of Obstetrics and Gynecology, vol. 214, no. 535, pp. 535-e4, 2016.

[69] A. Castañon, R. Landy, P. Brocklehurst et al., "Is the increased risk of preterm birth following excision for cervical intraepithelial neoplasia restricted to the first birth post treatment?" BJOG: An International Journal of Obstetrics and Gynaecology, vol. 122, no. 9, pp. 1191-1199, 2015.

[70] A. C. Gimovsky and V. Berghella, "Randomized controlled trial of prolonged second stage: extending the time limit vs usual guidelines," American Journal of Obstetrics and Gynecology, vol. 214, no. 3, pp. e1-361, 2016.

[71] U. Högberg and P. A. Holmgren, "Infant mortality of very preterm infants by mode of delivery, institutional policies and maternal diagnosis," Acta Obstetricia et Gynecologica Scandinavica, vol. 86, no. 6, pp. 693-700, 2007.

[72] U. Högberg, S. Håkansson, F. Serenius, and P. A. Holmgren, "Extremely preterm cesarean delivery: a clinical study," Acta Obstetricia et Gynecologica Scandinavica, vol. 85, no. 12, pp. 1442-1447, 2006.

[73] M. H. Malloy, "Impact of cesarean section on intermediate and late preterm births: United States, 2000-2003," Birth, vol. 36, no. 1, pp. 26-33, 2009.

[74] W. K. Axame, F. N. Binka, and M. Kweku, Determinants of Low Birthweight and Preterm Delivery in the Volta Region of Ghana: Evidence from Birth Records, Research Square, Durham, North Carolina, USA, 2020. 